\title{
Fear of COVID-19 and Mental Health: The Role of Mindfulness in During Times of Crisis
}

\author{
Hacer Belen ${ }^{1}$
}

Accepted: 15 December 2020 / Published online: 26 April 2021

(C) The Author(s), under exclusive licence to Springer Science+Business Media, LLC, part of Springer Nature 2021

\begin{abstract}
The novel coronavirus disease (COVID-19) has had a significant impact on all aspects of individuals' lives, particularly their mental health due to the fear associated with the pandemic. Thus, the current study explored the relationship between the fear of COVID-19 and aspects of mental health, namely anxiety and depression, and will consider whether this relationship can be mediated by mindfulness. Data were collected from a student sample of 355 participants (71.5\% female and $28.5 \%$ male) ranging between 18 and 41 years of age $(M=22.41 \pm 3.27)$, with participants completing a fear of COVID-19 scale (FCV-19S), Mindfulness Attention and Awareness Scale (MAAS), and the anxiety and depression subscale of the Symptom Checklist-90-Revised (SCL-90-R). In terms of the results, correlational analyses indicated that fear of COVID-19 is inversely associated with mindfulness, while positive correlations were found with anxiety and depression. Structural equation modeling analyses demonstrated that mindfulness mediated the relationship between fear of COVID-19 and depression and anxiety. Associated implications are further discussed.
\end{abstract}

Keywords Fear of COVID-19 $\cdot$ Mindfulness $\cdot$ Anxiety $\cdot$ Depression $\cdot$ Mediation

\section{Introduction}

SARS-CoV-2 is a rapidly spreading novel virus that transmits between humans through coughing, sneezing, and potentially contaminated surfaces. An outbreak of the virus was declared by the WHO on 30th of January, 2020 and, as of 1st of October of the same year, over 34 million cases of infection had been declared with a death toll of over 1 million worldwide (European Centre for Disease Prevention and Control, 2020). In order to prevent the spread of such a potentially fatal and, certainly, infectious disease, strict public health measures are being

Hacer Belen

hacerbelen@uludag.edu.tr

1 Educational Sciences, Psychological Counseling and Guidance, Bursa Uludag University, Ozluce, Gorukle Campus, 16059 Nilüfer, Bursa, Turkey 
taken including home confinement, social distancing, compulsory face mask usage, travel bans, and school suspensions (Wilder-Smith \& Freedman, 2020).

Although complying with prevention measures minimizes the spread of the virus, social distancing might also trigger certain negative psychological effects (Fusar-Poli et al., 2020). Additionally, with its high infection and mortality rates, the sudden collapse of industries and related financial loss might result in the further deterioration of such negative psychological effects through the current pandemic (Ahorsu, Imani, et al., 2020a). Essentially, a rise in mental health problems during such times of crisis is not a recent phenomenon. The literature documents that prior viral pandemics and epidemics have been highly impactful on the mental health of individuals and society (Chong et al., 2004). Thus, the COVID-19 pandemic is no exception in this regard. For instance, studies conducted in China during the first stage of the outbreak reported moderate to severe depressive, anxiety, and stress symptoms (Wang et al., 2020). Moreover, an array of studies documented that the current pandemic exacerbated poor mood states and psychological functioning such as confusion and anger (Brooks et al., 2020), suicidal thoughts and attempts (Bhuiyan et al., 2020), severe fatigue and sleep disturbance, lower self-efficacy and life satisfaction (Satici et al., 2020), and specifically fear (Rajkumar, 2020).

Fear is defined as the unpleasant emotional state that is elicited by a perceived threat (de Hoog et al., 2008). Due to the lack of control over the pandemic in terms of the current lack of an effective vaccine and treatment cure, individuals naturally began experiencing fear regarding developing the disease and associated fear of death (Khan et al., 2020). This recent concept refers to the fear of COVID-19 (Ahorsu, Lin, et al., 2020b) and its impact on individuals being examined throughout the pandemic and across the world (e.g., Masuyama et al., 2020; Pang et al., 2020; Perz et al., 2020; Sakib et al., 2020; Soraci et al., 2020; Winter et al., 2020). The literature suggested that while fear of COVID-19 propels individuals to observe the rules, such fear can evolve into a range of mental health problems (Huarcaya-Victoria et al., 2020). For instance, a growing body of research has demonstrated that fear regarding the current pandemic has facilitated the development of mental health issues, including psychological distress (Alyami et al., 2020; Bakioglu et al., 2020; Satici et al., 2020), panic disorder (Islam et al., 2020), insomnia (Şahin et al., 2020), post-traumatic stress symptoms (Bo et al., 2020; Hao et al., 2020; Liu et al., 2020), and particularly moderate to severe depressive symptoms (Belen, 2020; Holmes et al., 2020; Šljivo et al., 2020; Soraci et al., 2020) and anxiety (Cameron et al., 2020; Roy et al., 2020). Essentially, individuals experiencing life-threatening situations are at risk of developing anxiety and depression (Nickell 2004; Tsang et al., 2004). Additionally, home confinement and associated social and physical isolation and fear of contracting the virus themselves are critical risk factors for the development of anxiety and depression (Holmes et al., 2020).

Unsurprisingly, positive psychological strengths are critical to countering the negative effects of fear during such adverse situations as they lessen the psychological burden of prolonged distress (Polizzi et al., 2020). In this regard, one of the potential concepts that might help to cope with such fear is surely mindfulness. Mindfulness refers to the awareness of the present moment and acceptance of thoughts and feelings without judgment (Kabat-Zinn, 1990). The literature suggests that mindfulness is associated with an attitude of acceptance of difficult circumstances and emotions, which in turn facilitates effective responses to stressful stimuli (Bishop et al., 2004; Hafeman et al., 2020; Kabat-Zinn, 1990). Thus, numerous clinical and experimental studies have supported the idea that mindfulness enhances positive psychological strengths such as resilience to stress (Hafeman et al., 2020), life satisfaction (Tsafou et al., 2017), positive affect (Du et al., 2019), bravery and self-regulation (Pang \& Ruch, 2019), and self-compassion (Campos et al., 2016). Moreover, individuals with high levels of 
mindfulness are less likely to be overwhelmed by distressing feelings or circumstances such as depression (e.g., Alzahrani et al., 2020; Barnes \& Lynn, 2010; Carmody \& Baer, 2008; Fisak \& Von Lehe, 2012; Royuela-Colomer \& Calvete, 2016) and anxiety (MacDonald \& Olsen, 2020; Singh et al., 2020). Furthermore, numerous studies have provided support that mindfulness programs decreased individuals' levels of depression (Zemestani \& Nikoo, 2019) and anxiety symptoms (e.g., La Torre et al., 2020).

As related to psychological well-being, mindfulness is a critical concept during times of crisis, such as the COVID-19 pandemic. As noted, the current pandemic and associated fear have led society towards a proliferation of anxiety and depression. Since mindfulness offers helpful tools to face depression and anxiety, it may diminish the negative effect of fear of COVID-19 on individuals' mental health (Anālayo, 2020). For instance, mindfulness enables the attention to focus on the present moment (Svendsen et al., 2017). On the contrary, fear of COVID-19 is centered on the future, including contracting the virus or losing loved ones to the disease. In this regard, mindfulness might counteract the negative effect of fear associated with COVID-19 and indeed might contribute to individuals' mental health. Additionally, the immediate research priorities are to investigate the constructs that will inform interventions to cope with the fear of COVID-19 that will reduce the incidence of mental health problems such as anxiety and depression (Holmes et al., 2020).

\section{Present Study}

The main aim of this study was to examine the relationship between fear of COVID-19 and mental health indicators such as anxiety and depressive symptoms with a Turkish sample, as mediated by students' levels of mindfulness. The hypotheses of the study included (a) that fear of COVID-19 would be inversely related to mindfulness and positively related to anxiety and depression and (b) that mindfulness would mediate the relationship between fear of COVID19 and anxiety and depression. As no studies, per se, have examined such a relationship between these concepts, its exploration is certainly worth studying.

\section{Method}

\section{Participants}

The sample included 355 university students ( $71.5 \%$ female and $28.5 \%$ male) who were aged between 18 and 41 years $(M=22.41 \pm 3.27)$.

\section{Measures}

Fear of COVID-19 Scale (FCV-19S) FCV-19S is a seven-item self-report measure on which the items are scored using a five-point rating scale ( $1=$ strongly disagree and $5=$ strongly agree). The scale was developed to measure the extent to which a person fears COVID-19 and example items included "I am most afraid of coronavirus-19" (Ahorsu, Lin, et al., 2020b). The total score of the scale is obtained by summing the item scores of the respondents and higher scores on the scale demonstrate higher levels of COVID-19 fear. The Turkish adaptation of the scale demonstrated satisfactory psychometric properties of the scale (Satici et al., 2020) and the current study reports Cronbach's alpha of 0.86 . 
Mindful Attention and Awareness Scale (MAAS) MAAS is a fifteen-item self-report measure on which the items are scored using a six-point rating scale $(1=$ almost always and $6=$ almost never) (Brown \& Ryan, 2003). The scale was developed to measure the individuals' levels of mindfulness, and example items included "I find myself doing things without paying attention." The global score of the scale is obtained by calculating the mean score of each participant's responses and higher scores on the scale convey the higher levels of dispositional mindfulness. Validity and reliability studies of the Turkish adaptation of the scale yielded good psychometric qualities (Catak, 2012), and the current study reports Cronbach's alpha of 0.87.

Symptom Checklist-Revised (SCL-90-R) Anxiety and Depression Subscale The SCL-90-R is a ninety-item self-report measure on which the items are scored using a five-point rating scale $(0=$ not at all, $4=$ very much). The scale was developed to assess psychiatric problems of individuals and comprised eight subscales, namely somatization, anxiety, depression, obsessive-compulsive disorder, interpersonal sensitivity, hostility, phobic anxiety, paranoid ideation, and psychoticism (Derrogatis et al., 1973). The depression subscale encompasses 13 items to assess several core symptoms of depression, e.g., low affect and lack of interest that have occurred during the last 7 days, and example items included "crying easily." The anxiety dimension includes 10 items in order to measure anxiety symptoms, and items are exemplified as "nervousness or shakiness inside." The Turkish adaptation of the scale was performed by Dağ (1991), and the current study reports Cronbach's alphas of 0.92 and 0.93 for the subscales of depression and anxiety, respectively.

\section{Procedure}

Undergraduate students in Bursa Uludag University Educational Science Department were contacted by email lists and were invited to partake in the study. Data were collected through an online survey webpage between 2020 May 20 and 2020 May $31(N=355)$. The consent form to participate in the study was obtained via the first page of the online survey. Test administration was carried out via online software for the exchange of course credit. Participants were informed about the purpose of the study, the rights to withdraw during or after the involvement, and ensured about anonymity and confidentiality of storage and the disposal of the personal information.

\section{Data Analyses}

Before the main analyses, skewness and kurtosis statistics were analyzed to test the assumptions of normality. As Table 1 indicates, skewness and kurtosis values fall between $-/+1$ conveying no violation of the normal hypothesis (Hair et al., 2017). A two-step procedure employing structural equation modeling (SEM) has been conducted for mediation analyses (Anderson \& Gerbing, 1988). In SEM models, mindfulness, anxiety, and depression were represented by three parcels in order to improve the psychometric properties of the variables and diminish inflated measurement error. For such variables, items were assigned to the parcels based on the factorial algorithm technique (Matsunaga, 2008). This technique is utilized for parceling the items of unidimensional scales and parcels are created with regard to the magnitude of factor loadings based on factor analysis. Furthermore, fear of COVID-19 was represented in the model with seven indicators. 
Table 1 Descriptive statistics

\begin{tabular}{llllllll}
\hline & $\alpha$ & Min & Max & M & SD & Skew & Kurt \\
\hline COVID-19S & 0.86 & 7.00 & 33.00 & 17.12 & 5.78 & 0.28 & -0.38 \\
Depression & 0.92 & 0.00 & 45.00 & 20.45 & 11.83 & 0.14 & -0.91 \\
Anxiety & 0.93 & 0.00 & 40.00 & 9.89 & 9.41 & 0.93 & 0.51 \\
Mindfulness & 0.87 & 1.64 & 6.00 & 4.13 & 0.88 & -0.14 & -0.36 \\
\hline
\end{tabular}

Firstly, the measurement model was examined by performing confirmatory factor analysis in order to estimate the extent to which each latent variable is represented by its indicators. Secondly, the proposed causal model was examined by conducting structural equation modeling (SEM) with maximum likelihood estimation method and 95\% bias-corrected bootstrap to examine the significance of the mediating effect of mindfulness. In SEM analyses, fit indices were analyzed in order to evaluate the final model (Kline, 2011). Overall model fit was determined based on the criteria recommended by Hu and Bentler (1999). In terms of the criteria, insignificant and lower values for Chi-Square are preferable though this value is mostly affected by sample size (Tabachnick \& Fidell, 2001). Comparative fit index (CFI), incremental fit index (IFI), and Tucker-Lewis index (TLI) scores equal or greater than 0.95 demonstrates a good model-data fit, and a model is considered to be a good fit to the data when CMIN/DF $<3$ while RMSEA $\leq 0.08$ demonstrates adequate fit (MacCallum et al., 1996). All analyses were conducted by using SPSS AMOS 23 (Arbuckle, 2014).

\section{Results}

Findings from preliminary analyses showed that no severe violations of normal hypotheses were encountered (e.g., skewness from 0.93 to -0.14 , kurtosis from 0.51 to -0.91 ) (West et al., 1995). Descriptive statistics including Cronbach's alphas, minimum, maximum, mean, standard deviation, skewness, and kurtosis values for the study variables are presented in Table 1.

\section{Correlation Analyses}

Zero-order correlations between the variables were computed, and results demonstrated that fear of COVID-19 was positively correlated with depressive symptoms and anxiety while the inverse correlation was found between mindfulness with the correlation coefficients ranging between $r=0.38$ and $r=0.23$. Table 2 demonstrates the intercorrelations between the variables.

Table 2 Intercorrelations between main study variables

\begin{tabular}{lllll}
\hline & Fear of COVID-19 & Depression & Anxiety & Mindfulness \\
\hline Fear of COVID-19 & 1 & & & \\
Depression & $0.27^{* *}$ & & & \\
Anxiety & $0.38^{* *}$ & $0.74^{* *}$ & $-0.49^{* *}$ & 1 \\
Mindfulness & $-0.23^{* *}$ & $-0.54^{* *}$ & \\
\hline
\end{tabular}

Note. $* * . p<0.001$ 


\section{Measurement Model}

Measurement model was examined by performing confirmatory factor analyses (CFA) in order to evaluate whether the model adequately fits the data. The results revealed good modeldata fit: $\chi^{2}(94, N=355)=264.53, \chi 2 / \mathrm{df}=2.81, p<0.001$; $\mathrm{CFI}=0.96$; TLI $=0.95$; IFI $=$ $0.96 ;$ RMSEA $=0.07(90 \% \mathrm{CI}=0.061-0.082)$.

\section{Structural Model}

Structural equation modeling analyses were performed in order to test the mediator role of mindfulness. Thus, two possible structural models have been tested to compare the competing models and identify the most appropriate model in regard to the structural relations. First, a partial mediating effect of mindfulness in the relationship between fear of COVID-19 and depression and anxiety was tested as model 1 (M1), and results demonstrated good model-data fit with all significant paths between latent and observed variables except the path between fear of COVID-19 and depression: $\chi 2(95, N=355)=352.50, \chi^{2} / \mathrm{df}=3.71, p<0.001$; CFI $=$ 0.94; TLI $=0.92$; IFI $=0.93$; RMSEA $=0.08$ (90\% CI =0.078-0.097). Omitting the path between fear of COVID-19 and depression, the full mediating effect of mindfulness between fear of COVID-19 and depression, partial mediator role of mindfulness between fear of COVID-19 and anxiety was tested to compare competing models (M2) and results revealed a very satisfactory fit to the data: $\chi^{2}(95, N=355)=264.76, \chi 2 / \mathrm{df}=2.78, p<0.001 ; \mathrm{CFI}=$ $0.96 ; \mathrm{TLI}=0.95 ; \mathrm{IFI}=0.96 ; \mathrm{RMSEA}=0.07(90 \% \mathrm{CI}=0.061-0.081)$.

As Table 3 demonstrates, fit indices indicate a slight improvement for model 2 to model 1 and path between fear of COVID-19 and depression became nonsignificant supporting the full mediator role of mindfulness $(\beta=0.02, p>.05)$. In model 2 , fear of COVID-19 predicted mindfulness $(\beta=$ $-0.22, p<0.001)$ and anxiety $(\beta=0.25, p<0.001)$. Mindfulness negatively predicted anxiety $(\beta=$ $-0.44, p<0.001)$ and depression $(\beta=-0.21, p<0.001)$ as Fig. 1 demonstrates. More importantly, mindfulness mediated the relationship between fear of COVID-19, anxiety, and depression. $95 \%$ bias-corrected bootstrapping procedure was applied to determine the significance of mediating effect, and results indicated mindfulness significantly mediated in the relationship between fear of COVID-19, anxiety $(95 \% \mathrm{CI}=[0.05,0.15])$, and depression $(95 \% \mathrm{CI}=[0.20,0.34])$.

\section{Discussion}

The COVID-19 pandemic may exacerbate anxiety and depression symptoms among individuals for various reasons such as lockdowns (Meda et al., 2020) and the associated isolation (Hwang et al., 2020), fear of worthlessness, and fear of infection (Dubey et al., 2020). One of the critical antecedents of such mental health problems might include fear of COVID-19. Thus, the present study aimed to investigate whether (a) fear of COVID-19 is related to mental health

Table 3 Comparison of alternative models

\begin{tabular}{lllllllll}
\hline Model & $\chi 2$ & DF & $p$ & CMIN/DF & RMSEA & CFI & TLI & IFI \\
\hline M1 (Partial M) & 352.50 & 95 & $p<0.001$ & 3.71 & 0.08 & 0.94 & 0.92 & 0.93 \\
M2 (Full Mediation) & 264.76 & 95 & $p<0.001$ & 2.78 & 0.07 & 0.96 & 0.95 & 0.96 \\
\hline
\end{tabular}




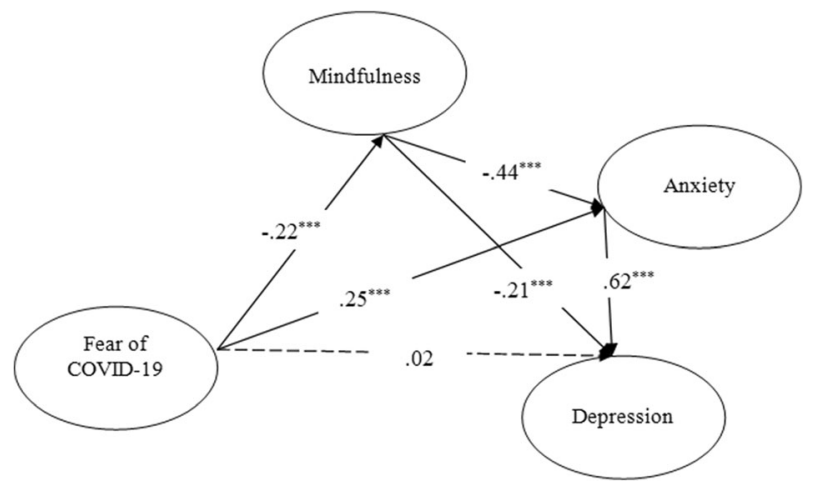

Fig. 1 Mediating effect of mindfulness between fear of COVID-19 and anxiety and depression. Note. Path coefficients were standardized; insignificant path lines were dashed; $* * * p<0.001$

indicators such as anxiety and depression symptoms and (b) whether mindfulness acts as a protective factor and mediates the relationship between fear of COVID-19 and anxiety and depression. In this regard, the current study reports two main results: (a) decreased fear of COVID-19 is related to increased mindfulness and decreased levels of anxiety and depressive symptoms, and (b) mindfulness mediates the relationship between fear of COVID-19 and anxiety and depression.

Concerning the first hypothesis of the study, participants who reported higher levels of fear of COVID-19 also reported higher levels of anxiety and depression, and indeed such findings are compatible with previous research. Several previous studies have reported that fear and panic concerning COVID-19 elevate the risk of developing mental health issues, including anxiety and depression (Ahorsu, Imani, et al., 2020a; Du et al., 2020; Guo et al., 2020; Huang \& Zhao, 2020; Lai et al., 2020; Liu et al., 2020; Lu et al., 2020; Pang et al., 2020). In terms of the findings regarding mindfulness, to the best of the knowledge, this is the first study to investigate the relationship between fear of COVID-19 and mindfulness. Thus, no empirical studies exist to support the findings of the current study despite conceptual overlaps between the two concepts. For instance, the fear associated with pandemic aligns with the preoccupation about the future, whether the individual or his/her loved ones contract the virus and develop the COVID-19 disease. On the contrary, mindfulness conveys the awareness and acceptance of the present moment that might help individuals to be less overwhelmed by predominant symptoms such as anxiety, despair, and depression that are present at the times of a global crisis (Behan, 2020). Thus, an inverse association between the constructs is apparent.

In accordance with the second hypothesis, the findings of the SEM analysis conveyed that mindfulness mediated the relationship between fear of COVID-19 and anxiety and depressive symptoms. This finding suggested that individuals who are mindful of the present moment are less affected by the negative consequences of fear regarding the COVID-19 pandemic in terms of developing anxiety and depressive symptoms, as mindfulness counteracts the negative psychological outcomes of such adverse conditions. The finding is meaningful in terms of the theoretical and empirical literature on mindfulness. Theoretically, mindfulness was suggested to be a useful skill that can offer a helpful way to adjust to such constant change and cope with anxiety and depression (Behan, 2020). Furthermore, the potential of mindfulness in terms of learning to face fear without either repressing it or acting it out can provide a tool to cope with anxiety and depression (Anālayo, 2020). Empirically, numerous studies demonstrated that increased levels of mindfulness are 
associated with decreased levels of anxiety and depression (Flett et al., 2020; Fong \& Ho, 2020; Li et al., 2020; MacDonald \& Olsen, 2020; Makadi \& Koszycki, 2020; Soo et al., 2020). Moreover, several studies highlighted the mitigative effects of mindfulness on interpersonal problems (Janovsky et al., 2019), psychological distress (Masuda \& Wendell, 2010), and, particularly, anxiety and depression (An et al., 2019; Lima et al., 2019). Taken together, the findings of the current study suggested that decreased levels of fear of COVID-19 contribute to greater levels of mindfulness, which in turn leads to a decreased risk of developing anxiety and depressive symptoms. Therefore, greater mindfulness might protect individuals from the negative effects of fear of COVID-19 and promote better mental health during the COVID-19 pandemic in general.

Given the scarcity of any research concerning the relationship between fear of COVID-19 and mindfulness, the findings of the current study are noteworthy. Among the strengths of the study was the use of scales with good psychometric properties, although employing only selfreport measures was clearly a limitation. Thus, employing various other methods, including qualitative designs, is recommended. Another limitation in this instance was the crosssectional nature of the study. In order to ascertain a causal relationship, studies with longitudinal and experimental designs need to be conducted. Moreover, although the recruitment targeted a homogenous sample in terms of the number of male and female participants, females outweighed males taking part in the study. Additionally, participants were only recruited from among university students which clearly might restrict the generalizability of the results. Thus, further studies should aim to recruit similar numbers of participants from both genders and more diverse samples, including older adults or a community sample to support the generalizability of the results to a larger population. Notwithstanding these limitations, the present study sheds light on the underlying mechanism behind the relationship between fear of COVID-19, mindfulness, and anxiety and depressive symptoms.

In conclusion, the current study has examined the mediating role of mindfulness in the relationship between fear of COVID-19 and mental health indicators, namely anxiety and depression. The results demonstrated that there is an association between fear of COVID-19 and mindfulness and experiencing a reduced fear associated with COVID-19 pandemic contributing to greater levels of mindfulness, which in turn contributes to decreased levels of anxiety and depression.

\section{Declaration}

Ethics Approval Ethical approval was obtained by the Bursa Uludag University Ethics Committee.

Conflict of Interest The author declares no competing interest.

\section{References}

Ahorsu, D. K., Imani, V., Lin, C. Y., Timpka, T., Broström, A., Updegraff, J. A., Årestedt, K., Grifiths, M. D., \& Pakpour, A. H. (2020a). Associations between fear of COVID-19, mental health, and preventive behaviours across pregnant women and husbands: An actor-partner interdependence modelling. International Journal of Mental Health and Addiction. Advance online publication. https://doi.org/10.1007/s11469-020-00340-x.

Ahorsu, D. K., Lin, C. Y., Imani, V., Saffari, M., Griffiths, M. D., \& Pakpour, A. H. (2020b). The fear of COVID-19 scale: Development and initial validation. International Journal of Mental Health and Addiction. Advance online publication. https://doi.org/10.1007/s11469-020-00270-8. 
Alyami, M., Henning, M., Krägeloh, C. U., \& Alyami, H. (2020). Psychometric evaluation of the Arabic version of the fear of COVID-19 scale. International Journal of Mental Health and Addiction. Advance online publication. https://doi.org/10.1007/s11469-020-00316-x.

Alzahrani, A. M., Hakami, A., AlHadi, A., Batais, M. A., Alrasheed, A. A., \& Almigbal, T. H. (2020). The interplay between mindfulness, depression, stress and academic performance in medical students: A Saudi perspective. PLoS One, 15(4), 1-11. https://doi.org/10.1371/journal.pone.0231088.

An, Y., Fu, G., Yuan, G., Zhang, Q., \& Xu, W. (2019). Dispositional mindfulness mediates the relations between neuroticism and posttraumatic stress disorder and depression in Chinese adolescents after a tornado. Clinical Child Psychology and Psychiatry, 24(3), 482-493. https://doi.org/10.1177/1359104518822672.

Anālayo, B. (2020). Somatics of early Buddhist mindfulness and how to face anxiety. Mindfulness, 11, 15201526. https://doi.org/10.1007/s12671-020-01382-x.

Anderson, J. C., \& Gerbing, D. W. (1988). Structural equation modeling in practice: A review and recommended two-step approach. Psychological bulletin, 103(3), 411.

Bakioğlu, F., Korkmaz, O., \& Ercan, H. (2020). Fear of COVID-19 and positivity: Mediating role of intolerance of uncertainty, depression, anxiety, and stress. International Journal of Mental Health and Addiction. Advance online publication. https://doi.org/10.1007/s11469-020-00331-y.

Barnes, S. M., \& Lynn, S. J. (2010). Mindfulness skills and depressive symptoms: A longitudinal study. Imagination, Cognition and Personality, 30(1), 77-91. https://doi.org/10.2190/IC.30.1.e.

Behan, C. (2020). The benefits of meditation and mindfulness practices during times of crisis such as Covid-19. Irish Journal of Psychological Medicine, 37, 1-3. https://doi.org/10.1017/ipm.2020.38.

Belen, H. (2020). Self-blame regret, fear of COVID-19 and mental health during post-peak pandemic. Research Square. https://doi.org/10.21203/rs.3.rs-56485/v1.

Bhuiyan, A. I., Sakib, N., Pakpour, A. H., Griffiths, M. D., \& Mamun, M. A. (2020). COVID-19-related suicides in Bangladesh due to lockdown and economic factors: Case study evidence from media reports. International Journal of Mental Health and Addiction. Advance online publication. https://doi.org/10. 1007/s11469-020-00307-y.

Bishop, S. R., Lau, M., Shapiro, S., Carlson, L., Anderson, N. D., Carmody, J., Segal, Z. V., Abbey, S., Speca, M., Velting, D., \& Devins, G. (2004). Mindfulness: A proposed operational definition. Clinical Psychology: Science and Practice, 11(3), 230-241.

Bo, H. X., Li, W., Yang, Y., Wang, Y., Zhang, Q., Cheung, T., Wu, X., \& Xiang, Y. T. (2020). Posttraumatic stress symptoms and attitude toward crisis mental health services among clinically stable patients with COVID-19 in China. Psychological Medicine. Advanced Online Publication, 1-2. https://doi.org/10.1017/ S0033291720000999.

Brooks, S. K., Webster, R. K., Smith, L. E., Woodland, L., Wessely, S., Greenberg, N., \& Rubin, G. J. (2020). The psychological impact of quarantine and how to reduce it: Rapid review of the evidence. The Lancet, 395(1227), 912-920. https://doi.org/10.1016/S0140-6736(20)30460-8.

Brown, K. W., Ryan, R. M. (2003). The benefits of being present: Mindfulness and its role in psychological wellbeing. Journal of Personality and Social Psychology, 84 (4), 822-848.

Cameron, E., Joyce, K., Delaquis, C., Reynolds, K., Protudjer, J., \& Roos, L. E. (2020). Maternal psychological distress \& mental health services use during the COVID-19 pandemic. PsyArxiv. https://doi.org/10.31234/ osf.io/a53zb.

Campos, D., Cebolla, A., Quero, S., Bretón-López, J., Botella, C., Soler, J., García-Campayo, J., Demarzo, M., \& Baños, R. M. (2016). Meditation and happiness: Mindfulness and self-compassion may mediate the meditation-happiness relationship. Personality and Individual Differences, 93, 80-85. https://doi.org/10. 1016/j.paid.2015.08.040.

Carmody, J., \& Baer, R. A. (2008). Relationships between mindfulness practice and levels of mindfulness, medical and psychological symptoms and well-being in a mindfulness-based stress reduction program. Journal of Behavioral Medicine, 31(1), 23-33. https://doi.org/10.1007/s10865-007-9130-7.

Catak, P. D. (2012). The Turkish version of mindful attention awareness scale: Preliminary findings. Mindfulness, 3 (1), 1-9.

Chong, M.-Y., Wang, W.-C., Hsieh, W.-C., Lee, C-Y., Chiu N.-M., Yeh, W.-C., Huang, T.-L., Wen, J.-K., Chen, C.-L. (2004). Psychological impact of severe acute respiratory syndrome on health workers in a tertiary hospital. British Journal of Psychiatry 185 (2), 127-133.

Dağ, I. (1991). Belirti Tarama Listesi (Scl-90-R)'nin üniversite öğrencileri için güvenirliği ve geçerliği [reliability and validity of the symptom checklist (SCL-90-R) for university students]. Türk Psikiyatri Dergisi, 2(1), 5-12.

de Hoog, N., Stroebe, W., \& de Wit, J. B. (2008). The processing of fear-arousing communications: How biased processing leads to persuasion. Social Influence, 3(2), 84-113. https://doi.org/10.1080/15534510802185836.

Derrogatis, L., Lipman, R., \& Covi, I. J. P. B. (1973). The SCL-90: An outpatient psychiatric rating scale. Psychopharmacology Bulletin, 9(1), 13-28. 
Du, J., An, Y., Ding, X., Zhang, Q., \& Xu, W. (2019). State mindfulness and positive emotions in daily life: An upward spiral process. Personality and Individual Differences, 141, 57-61. https://doi.org/10.1016/j.paid.2018.11.037.

Du, J., Dong, L., Wang, T., Yuan, C., Fu, R., Zhang, L., Liu, B., Zhang, M., Yin, Y., Qin, J., Bouey, J., Zhao, M., \& Li, X. (2020). Psychological symptoms among frontline healthcare workers during COVID-19 outbreak in Wuhan. General Hospital Psychiatry, 67, 144-145. https://doi.org/10.1016/j.genhosppsych.2020.03.011.

Dubey, S., Biswas, P., Ghosh, R., Chatterjee, S., Dubey, M. J., Chatterjee, S., Dubey, M. J., Chatterjee, S., Lahiri, D., \& Lavie, C. J. (2020). Psychosocial impact of COVID-19. Diabetes and Metabolic Syndrome: Clinical Research and Reviews, 14, 779-788. https://doi.org/10.1016/j.dsx.2020.05.035.

European Centre for Disease Prevention and Control. (2020). COVID-19: Situation update worldwide. Retrieved October 1, 2020, from: https://www.ecdc.europa.eu/en/geographical -distribution-2019-ncov-cases

Fisak, B., \& Von Lehe, A. C. (2012). The relation between the five facets of mindfulness and worry in a nonclinical sample. Mindfulness, 3(1), 15-21. https://doi.org/10.1007/s12671-011-0075-0.

Flett, G. L., Nepon, T., Hewitt, P. L., \& Rose, A. L. (2020). Why perfectionism is antithetical to mindfulness: A conceptual and empirical analysis and consideration of treatment implications. International Journal of Mental Health and Addiction. Advance online publication. https://doi.org/10.1007/s11469-020-00252-w.

Fong, T. C., \& Ho, R. T. (2020). Mindfulness facets predict quality of life and sleep disturbance via physical and emotional distresses in Chinese cancer patients: A moderated mediation analysis. Psycho-Oncology, 29(5), 894-901. https://doi.org/10.1002/pon.5363.

Fusar-Poli, P., Brambilla, P., \& Solmi, M. (2020). Learning from COVID-19 pandemic in Northern Italy: Impact on mental health and clinical care. Journal of Affective Disorders, 275, 78-79. https://doi.org/10.1016/j.jad.2020.06.028.

Guo, J., Liao, L., Wang, B., Li, X., Guo, L., Tong, Z., Guan, Q., Zhou, M., Wu, Y., Zhang, J., \& Gu, Y. (2020). Psychological effects of COVID-19 on hospital staff: A national cross-sectional survey of China mainland. Lancet. https://doi.org/10.2139/ssrn.3550050.

Hafeman, D. M., Ostroff, A. N., Feldman, J., Hickey, M. B., Phillips, M. L., Creswell, D., Birmaher, B., \& Goldstein, T. R. (2020). Mindfulness-based intervention to decrease mood lability in at-risk youth: Preliminary evidence for changes in resting state functional connectivity. Journal of Affective Disorders, 276, 23-29. https://doi.org/10.1016/j.jad.2020.06.042.

Hair Jr, J. F., Sarstedt, M., Ringle, C. M., \& Gudergan, S. P. (2017). Advanced issues in partial least squares structural equation modeling. saGe publications.

Hao, X., Zhou, D., Li, Z., Zeng, G., Hao, N., Li, E., Li, W., Deng, A., Lin, M., \& Yan, B. (2020). Severe psychological distress among patients with epilepsy during the COVID-19 outbreak in Southwest China. Epilepsia, 61(6), 1166-1173. https://doi.org/10.1111/epi.16544.

Holmes, E. A., O'Connor, R. C., Perry, V. H., Tracey, I., Wessely, S., Arseneault, L., Ballard, C., Christensen, H., Silver, R. C., Everall, I., Ford, T., John, A., Kabir, T., King, K., Madan, I., Michie, S., Przybylski, A. K., Shafran, R., Sweeney, A., \& Bullmore, E. (2020). Multidisciplinary research priorities for the COVID-19 pandemic: A call for action for mental health science. The Lancet Psychiatry, 7(6), 547-560. https://doi.org/ 10.1016/S2215-0366(20)30168-1.

Hu, L. T., \& Bentler, P. M. (1999). Cutoff criteria for fit indexes in covariance structure analysis: Conventional criteria versus new alternatives. Structural equation modeling: a multidisciplinary journal, 6(1), 1-55.

Huang, Y., \& Zhao, N. (2020). Generalized anxiety disorder, depressive symptoms and sleep quality during COVID-19 outbreak in China: A web-based cross-sectional survey. Psychiatry Research, 288, 1-6. https:// doi.org/10.1016/j.psychres.2020.112954.

Huarcaya-Victoria, J., Villarreal-Zegarra, D., Podestà, A., \& Luna-Cuadros, M. A. (2020). Psychometric properties of a Spanish version of the fear of COVID-19 scale in general population of Lima. Peru. International Journal of Mental Health and Addiction. Advance online publication. https://doi.org/10. 1007/s11469-020-00354-5.

Hwang, T. J., Rabheru, K., Peisah, C., Reichman, W., \& Ikeda, M. (2020). Loneliness and social isolation during the COVID-19 pandemic. International Psychogeriatrics. Advance online publications., 32, 1217-1220. https://doi.org/10.1017/S1041610220000988.

Islam, M. S., Ferdous, M. Z., \& Potenza, M. N. (2020). Panic and generalized anxiety during the COVID-19 pandemic among Bangladeshi people: An online pilot survey early in the outbreak. Journal of Affective Disorders, 276, 30-37. https://doi.org/10.1016/j.jad.2020.06.049.

Janovsky, T., Clark, G. I., \& Rock, A. J. (2019). Trait mindfulness mediates the relationship between early maladaptive schema and interpersonal problems. Australian Psychologist, 54(5), 391-401. https://doi.org/ 10.1111/ap.12390.

Kabat-Zinn, J. (1990). Using the wisdom of your body and mind to face stress, pain, and illness. Bantam Doubleday Dell.

Khan, K. S., Mamun, M. A., Griffiths, M. D., \& Ullah, I. (2020). The mental health impact of the COVID-19 pandemic across different cohorts. International Journal of Mental Health and Addiction. Advance online publication. https://doi.org/10.1007/s11469-020-00367-0. 
Lai, J., Ma, S., Wang, Y., Cai, Z., Hu, J., Wei, N., Wu, J., Du, H., Chen, T., Li, R., Tan, H., Kang, L., Yao, L., Huang, M., Wang, H., Wang, G., Liu, Z., Hu, S. (2020). Factors associated with mental health outcomes among health care workers exposed to coronavirus disease 2019. JAMA Network Open, 3 (3), e203976.

La Torre, G., Raffone, A., Peruzzo, M., Calabrese, L., Cocchiara, R. A., D’Egidio, V., Leggieri, P. F., Dorelli, B., Zaffina, S., \& Mannoci, A. (2020). Yoga and mindfulness as a tool for influencing affectivity, anxiety, mental health, and stress among healthcare workers: Results of a single-arm clinical trial. Journal of Clinical Medicine, 9(4), 1-13. https://doi.org/10.3390/jcm9041037.

Li, G., Jiang, Z., Han, X., Shang, X., Tian, W., Kang, X., \& Fang, M. (2020). A moderated mediation model of perceived stress, negative emotions and mindfulness on fertility quality of life in women with recurrent pregnancy loss. Quality of Life Research, 29, 1775-1787.

Lima, S., Garrett, C., Machado, J. C., Vilaça, M., \& Pereira, M. G. (2019). Quality of life in patients with mild Alzheimer disease: The mediator role of mindfulness and spirituality. Aging \& Mental Health. Advance online publication., 24, 2103-2110. https://doi.org/10.1080/13607863.2019.1650891.

Liu, D., Baumeister, R. F., Veilleux, J. C., Chen, C., Liu, W., Yue, Y., Zhang, S. (2020). Risk factors associated with mental illness in hospital discharged patients infected with COVID-19 in Wuhan, China. Psychiatry Research 292, 113297.

Lu, W., Wang, H., Lin, Y., \& Li, L. (2020). Psychological status of medical workforce during the COVID-19 pandemic: A cross-sectional study. Psychiatry Research, 288, 1-5. https://doi.org/10.1016/j.psychres.2020.112936.

MacCallum, R. C., Browne, M. W., \& Sugawara, H. M. (1996). Power analysis and determination of sample size for covariance structure modeling. Psychological Methods, 1(2), 130.

MacDonald, H. Z., \& Olsen, A. (2020). The role of attentional control in the relationship between mindfulness and anxiety. Psychological Reports, 123(3), 759-780. https://doi.org/10.1177/0033294119835756.

Makadi, E., \& Koszycki, D. (2020). Exploring connections between self-compassion, mindfulness, and social anxiety. Mindfulness, 11(2), 480-492. https://doi.org/10.1007/s12671-019-01270-z.

Masuda, A., \& Wendell, J. W. (2010). Mindfulness mediates the relation between disordered eating-related cognitions and psychological distress. Eating Behaviors, 11(4), 293-296. https://doi.org/10.1016/j.eatbeh. 2010.07.001.

Masuyama, A., Shinkawa, H., \& Kubo, T. (2020). Validation and psychometric properties of the Japanese version of the fear of COVID-19 scale among adolescents. International Journal of Mental Health and Addiction. Advance online publication. https://doi.org/10.1007/s11469-020-00368-z.

Meda, N., Pardini, S., Slongo, I., Bodini, L., Rigobello, P., Visioli, F., \& Novara, C. (2020). COVID-19 and depressive symptoms in students before and during lockdown. MedRxiv. https://doi.org/10.1101/2020.04.27. 20081695.

Nickell, L. A. (2004). Psychosocial effects of SARS on hospital staff: survey of a large tertiary care institution. Canadian Medical Association Journal, 170 (5), 793-798.

Pang, D., \& Ruch, W. (2019). The mutual support model of mindfulness and character strengths. Mindfulness, 10(8), 1545-1559. https://doi.org/10.1007/s12671-019-01103-z.

Pang, N. T. P., Kamu, A., Hambali, N. L. B., Mun, H. C., Kassim, M. A., Mohamed, N. H., Ayu, F., Abdul Rahim, S. S., Omar, A., \& Jeffree, M. S. (2020). Malay version of the fear of COVID-19 scale: Validity and reliability. International Journal of Mental Health and Addiction. Advance online publication. https://oi. org/10.1007/s11469-020-00355-4.

Perz, C. A., Lang, B. A., \& Harrington, R. (2020). Validation of the fear of COVID-19 scale in a US college sample. International Journal of Mental Health and Addiction. Advance online publication. https://doi.org/ 10.1007/s11469-020-00356-3.

Polizzi, C., Lynn, S. J., \& Perry, A. (2020). Stress and coping in the time of COVID-19: Pathways to resilience and recovery. Clinical Neuropsychiatry, 17(2), 59-62.

Rajkumar, R. P. (2020). COVID-19 and mental health: A review of the existing literature. Asian Journal of Psychiatry, 52, 1-5. https://doi.org/10.1016/j.ajp.2020.102066.

Roy, D., Tripathy, S., Kar, S. K., Sharma, N., Verma, S. K., \& Kaushal, V. (2020). Study of knowledge, attitude, anxiety \& perceived mental health care need in Indian population during COVID-19 pandemic. Asian Journal of Psychiatry, 51, 1-7. https://doi.org/10.1016/j.ajp.2020.102083.

Royuela-Colomer, E., \& Calvete, E. (2016). Mindfulness facets and depression in adolescents: Rumination as a mediator. Mindfulness, 7(5), 1092-1102. https://doi.org/10.1007/s12671-016-0547-3.

Şahin, M. K., Aker, S., Șahin, G., \& Karabekiroğlu, A. (2020). Prevalence of depression, anxiety, distress and insomnia and related factors in healthcare workers during COVID-19 pandemic in Turkey. Journal of Community Health. Advance online publication., 45, 1168-1177. https://doi.org/10.1007/s10900-02000921-w.

Sakib, N., Bhuiyan, A. I., Hossain, S., Al Mamun, F., Hosen, I., Abdullah, A. H., Sarker, M. A., Mohiuddin, M. S., Rayhan, I., Hossain, M., Sikder, M. T., Gozal, D., Muhit, M., Shariful Islam, S. M., Griffiths, M. D., Pakpour, A. H., \& Mamun, M. A. (2020). Psychometric validation of the Bangla fear of COVID-19 scale: 
Confirmatory factor analysis and Rasch analysis. International Journal of Mental Health and Addiction. Advance online publication. https://doi.org/10.1007/s11469-020-00289-x.

Satici, B., Gocet-Tekin, E., Deniz, M., \& Satici, S. (2020). Adaptation of the fear of COVID-19 scale: Its association with psychological distress and life satisfaction in Turkey. International Journal of Mental Health and Addiction. Advance online publication. https://doi.org/10.1007/s11469-020-00294-0.

Singh, R., Singh, B., Mahato, S., \& Hambour, V. K. (2020). Social support, emotion regulation and mindfulness: A linkage towards social anxiety among adolescents attending secondary schools in Birgunj, Nepal. PLoS One, 15(4), 1-11. https://doi.org/10.1371/journal.pone.0230991.

Šljivo, A., Kačamaković, M., Quraishi, I., \& Džubur Kulenović, A. (2020). Fear and depression among residents of Bosnia and Herzegovina during Covid-19 outbreak-internet survey. Psychiatria Danubina, 32(2), 266272. https://doi.org/10.24869/psyd.2020.266.

Soo, C., Kiernan, M., \& Anderson, V. (2020). Trait mindfulness as a mediator of anxiety and psychosocial functioning in young people with acquired brain injury. Developmental Neurorehabilitation, 23(4), 231239. https://doi.org/10.1080/17518423.2019.1645225.

Soraci, P., Ferrari, A., Abbiati, F. A., Del Fante, E., De Pace, R., Urso, A., \& Griffiths, M. D. (2020). Validation and psychometric evaluation of the Italian version of the fear of COVID-19 scale. International Journal of Mental Health and Addiction. Advance online publication. https://doi.org/10.1007/s11469-020-00277-1.

Svendsen, J. L., Kvernenes, K. V., Wiker, A. S., \& Dundas, I. (2017). Mechanisms of mindfulness: Rumination and self-compassion. Nordic Psychology, 69(2), 71-82. https://doi.org/10.1080/19012276.2016.1171730.

Tabachnick, B. G., \& Fidell, L. S. (2001). SAS for windows workbook for Tabachnick and Fidell using multivariate statistics. Allyn and Bacon.

Tsafou, K. E., Lacroix, J. P., Van, E. R., Vinkers, C. D., \& De Ridder, D. T. (2017). The relation of trait and state mindfulness with satisfaction and physical activity: A cross-sectional study in 305 Dutch participants. Journal of Health Psychology, 22(10), 1221-1232.

Tsang, H. W., Scudds, R. J., \& Chan, E. Y. (2004). Psychosocial impact of SARS. Emerging Infectious Diseases, 10, 1326-1327.

Wang, C., Pan, R., Wan, X., Tan, Y., Xu, L., Ho, C. S., \& Ho, R. C. (2020). Immediate psychological responses and associated factors during the initial stage of the 2019 coronavirus disease (COVID-19) epidemic among the general population in China. International Journal of Environmental Research and Public Health, 17(5), 1-25. https://doi.org/10.3390/ijerph17051729.

West, S. G., Finch, J. F., \& Curran, P. J. (1995). Structural equation models with nonnormal variables: Problems and remedies.

Wilder-Smith, A., \& Freedman, D. O. (2020). Isolation, quarantine, social distancing and community containment: Pivotal role for old-style public health measures in the novel coronavirus (2019-nCoV) outbreak. Journal of Travel Medicine, 27(2), 1-4. https://doi.org/10.1093/jtm/taaa020.

Winter, T., Riordan, B., Pakpour, A., Griffiths, M., Mason, A., Poulgrain, J., \& Damian, S. (2020). Evaluation of the English version of the fear of COVID-19 scale and its relationship with behavior change and political beliefs. International Journal of Mental Health and Addiction. Advance online publication. https://doi.org/ 10.1007/s11469-020-00342-9.

Zemestani, M., \& Nikoo, Z. F. (2019). Effectiveness of mindfulness-based cognitive therapy for comorbid depression and anxiety in pregnancy: A randomized controlled trial. Archives of Women's Mental Health, 23, 207-214. https://doi.org/10.1007/s00737-019-00962-8.

Publisher's Note Springer Nature remains neutral with regard to jurisdictional claims in published maps and institutional affiliations. 